\title{
Sürdürülebilir Kalkınma Alanındaki Yayınların R Programı ile Bibliyometrik Analizi
}

\author{
DOI: 10.26466/opus.707518 \\ * \\ Ceren Kocabaš - Gamze Alkan** \\ * Dr Öğr. Görevlisi, Akdeniz Üniversitesi, Antalya \\ E-Posta: cerenkocabas@akdeniz.edu.tr \\ ORCID: 0000-0003-2785-4359 \\ ** Doktora Öğrencisi Akdeniz Üniversitesi, Sosyal Bilimler Enstitüsü \\ E-Posta: gamzeaalkan@gmail.com \\ ORCID: 0000-0001-9624-084X
}

\begin{abstract}
Öz
Insan ihtiyaçlarının sınırsız, doğal kaynakların sınırlı olması ve dünya nüfusunun hızla artmaya devam etmesi, iklim değişikliklerine sebep olmuş, kaynak-ihtiyaç dengesini sarsmıştır. Bu durum, "sürdürülebilir kalkınma" kavramını ortaya çıkarmıştır. Çalışmada, ekonomi alanında sürdürülebilir kalkınma ile ilgili yayınlanan çalışmalara ait bibliyometrik özelliklerin belirlenmesi amaçlanmaktadır. 2000-2019 yılları arasında Web of Science (WOS) veri tabanında "sürdürülebilir kalkınma" konu başlığında yayınlanmış 2511 makaleye bibliyometrik analiz uygulanmıştır. Analiz sonucuna göre; incelenen 2511 makale 456 farklı dergide yayınlanmıştır. Yayın başına ortalama atıf sayısı 16,38'dür. Makale başına düşen yazar sayısı da 2,07'dir. 2007 yılından itibaren "sürdürülebilir kalkınma" kelimesi alanda daha sık kullanılmaya başlanmış, 2018-2019 yıllarında ise oldukça popüler hale gelmiştir. "Etki, büyüme, politika, yönetim" yine son yillarda alanda en sik kullanilan kelimelerdir. Dalia Streimikiene en fazla makale yayını yapan, İbrahim Dinçer alan ile ilgili en çok atıf alan yazardır. İngiltere, ABD, Çin, Almanya, Hollanda "sürdürülebilir kalkınma" ile ilgili en fazla makaleye sahip ülkelerdir. Alanla ilgili atıfların toplam sayılarına göre; Türkiye 13. sirada yer almaktadır. "Energy Policy" en fazla makale yayın yapan dergidir. "Ecological Economics" en fazla atıf alan dergidir.
\end{abstract}

Anahtar Kelimeler: Sürdürülebilirlik, Sürdürülebilir Kalkınma, Bibliyometri 


\title{
Bibliometric Analysis of Publications in Sustainable Development with R Program
}

\begin{abstract}
The human needs are unlimited, the natural resources are limited, and the world population continues to increase rapidly, causing climate changes and shaking the resource-need balance. This situation brought out the concept of "Sustainable Development In the study, it is aimed to determine the bibliometric features of published studies on sustainable development in the field of economy. Between 2000 and 2019, bibliometric analysis was applied to 2511 articles published under the title of "Sustainable Development" in the Web of Science (WOS) database. According to the analysis result; 2511 articles examined were published in 456 different journals. The average number of citations per publication is 16.38. The number of authors per article is 2.07. Since 2007, the word "Sustainable Development" has been used more frequently in the field and has become very popular in 2018-2019. "Impact, growth, policy, management" are the most frequently used words in the field in recent years. Dalia Streimikiene publishes the most articles. Ibrahim Dinçer is the most cited author of the field. Britain, USA, China, Germany, Netherlands are the countries with the most articles on "Sustainable Development". According to the total number of citations related field Turkey rank is 13. "Energy Policy" is the magazine that publishes the most articles. "Ecological Economics" is the most cited magazine.
\end{abstract}

Keywords: Sustainablity, Sustainable Development, Bibliometrics 


\section{Giriş}

Gelecek kuşakların ihtiyaçlarını karşılayabilme olanağından ödün vermeden günümüz kuşaklarının ihtiyaçlarını karşılayabilecek kalkınma modeli olarak tanımlanan sürdürülebilir kalkınma, özellikle 20. yüzyıl sonlarında dünyada bilinirliğini arttırmıştır. 1990'lı yıllarda imzalanan uluslararası antlaşmalar ile küresel bir uygulama planı haline gelmiştir (T.C. Strateji ve Bütçe Başkanlığı, 2020).

Sürdürülebilirlik kavramınn özellikle 19. yüzyıl başlarında literatürde yer almaya başladığı görülmektedir. 1912 ve 1920 yıllarında A. Pigou'nun ekonomi bilimi üzerine yazdığı kitaplarda sürdürülebilirlik düşüncesinin temelleri bulunmaktadır (Pigou, 1912; Pigou, 1920). Sürdürülebilir kalkınma düşüncesinin kavramsallaşması başta Birleşmiş Milletler olmak üzere, uluslararası kuruluşların yapmış olduğu çeşitli konferanslar sonucunda biçimlenmiştir (Bozlağan, 2005: 1014-1017). 20. yüzyıldan itibaren dünya nüfusu artarken ekonomik ve sosyal açıdan ülkeler kalkınmaya başlamışlardır. Ancak insan ihtiyaçlarının sınırsız, doğal kaynakların sınırlı olması ve dünya nüfusunun hızla artmaya devam etmesi; doğal kaynakların azalmasına ve iklim değişikliklerine neden olmaya başlamıştır. Hızla gelişen sanayileşme ve kentleşme, ülke ekonomilerinin gelişmesi, yeni teknolojiler ve tarımda modernleşme kaynak-ihtiyaç dengesini sarsmıştır. Sosyal refahı elde etme gayretleri insanlığın geleceğini ipotek altına almıştır. Bu durum, "sürdürülebilir kalkınma" kavramlarını ortaya çıkarmıştır. Bu kavram aslında resmi olarak ilk defa 1987'de Dünya Çevre ve Kalkınma Komisyonunda dile getirilmiş ve o günden bu güne en fazla kullanılan ve kabul edilen kavram olmuştur (Baykal ve Baykal, 2008, s. 10). 1987 yılında Dünya Çevre ve Kalkınma Komisyonu'nun raporunda sürdürülebilir kalkınma tanımı kapsamlı olarak yapılmıştır. Rapor tanımına göre; "gelecek kuşakların gereksinimlerini karşılayabilme olanağını tehlikeye sokmadan günümüz ihtiyaçlarını karşılayabilme" olarak tanımlanmıştır (WCED, 1987). Raporda sürdürülebilir kalkınmanın hedefleri aşağıdaki gibi sıralanmıştır (Aksu, 2011);

1. Büyümeyi canlandırmak

2. Büyümenin kalitesini değiştirmek

3. İş bulma, yiyecek, enerji, su ve sağlık konularındaki temel ihtiyaçları karşılamak

4. Sürdürülebilir bir nüfus düzeyini garanti altına almak 
5. Kaynak tabanını korumak ve zenginleştirmek

6. Teknolojiyi yeniden yönlendirmek ve riski yönetmek

7. Karar verme sürecinde çevre ve ekonomiyi birleştirmek

Belirtilen hedeflere göre; sürdürülebilir kalkınma ile sadece çevre ve ekonomi arasındaki ilişkinin vurgulanmadığı, aynı zamanda kavramın toplumsal, siyasal ve kültürel boyutlarının da bulunduğu ifade edilmiştir. (Bahçeci ve Görmez, 2019, s. 2311).

Çalışmada ekonomi alanında "sürdürülebilir kalkınma" ile ilgili 20002019 yıllarında Web of Science (WOS) veri tabanında yayınlanan makalelerin bibliyometrik analizi yapılmıştır. Bibliyometri terimi, 1969 yılında Alan Pritchard tarafından ileri sürülmüş olup, Pritchard "istatistiksel bibliyografya" terimi yerine "bibliyometri" teriminin kullanılmasını önermiştir (Lawani, 1981: 294). İlk bibliyometrik çalışma ise; 1917 yılında Cole ve Eales tarafından yapılmış olup, 1550-1860 yılları arasında karşılaştırmalı anatomi alanında yayınlanan araştırmalara ait istatistiksel bir analiz yapmışlardır (Lawani, 1981: 295). Bibliyometri'nin temel amacı, çeşitli dönemlerde yayınlanmış dergi, kitap gibi yayınların ya da belgelerin belirli kriterleri baz alınarak, bilimsel dökümantasyonun, bilimsel iletişime ilişkin bulguların iyileştirilmesi amacı ile sayısal yöntemler ile analiz edilmesidir (Osareh, 1996, s. 149-150). Literatürde ekonomi alanında sürdürülebilir kalkınma ile ilgili yapılan çalışmaların genel özelliklerinin çeşitli bibliyometri yasaları çerçevesinde belirlenmesine yönelik kapsamlı ve güncel bir çalışmanın yer almadığı görülmüştür. Bu nedenle, bu çalışmanın söz konusu boşluğun doldurulmasına katkı sağlayacağı düşünülmektedir. Ayrıca çalışmanın sürüdürlebilir kalkınma alanına ait çalışmaların yönünü ve eğilimlerini göstermesi açısından ileride araştırma yapmayı düşünen araştırmacılara yol gösterici olması yönünden fayda sağlayacağı düşünülmektedir.

\section{Literatür}

Literatürde sürdürülebilir kalkınma konularının kullanıldığı pekçok çalışma bulunmaktadir.

Saeed-Ul-Hassan, Haddawy , Kuinkel , Sedhai (2011), sürdürülebilir kalkınma ile ilgili araştırma faaliyetlerinin bibliyometrik analizini yapmıştırlar. 2000-2008 yılları arasında sürdürülebilir kalkınma konusunda en fazla yayın yapan dokuz ülkenin araştırma faaliyetlerini incelemişlerdir. Ele alınan 9 
ülke; ABD, İngiltere, Çin, Kanada, Almanya, Avustralya, Japonya, Fransa ve İspanya'dır. Çalışma, yapılan yayınlar ve atıflar açısından analiz edilmiştir. ABD'nin yayın sayısı ve atıf sayısı bakımından açık ara önde gelen ülke olduğu, Çin ve İngiltere'nin (2003-2008) yayın sayılarının birbirine yakın olmasına rağmen, İngiltere' nin atıf sayılarında diğer ülkelerden oldukça ileride olduğu ve son yıllarda liderliğini arttırdığı sonucuna ulaşılmıştır.

Saeed-Ul Hassan, Haddawy, Zhu (2014), bilimsel literatür kullanarak Dünya genelinde sürdürülebilir kalkınma ile ilgili araştırma faaliyetlerinin bibliyometrik bir çalışmasını yapmışlardır. Çalışma, 2000-2010 yılları arasında Scopus veritabanındaki veriler kullanılarak gerçekleştirilmiştir. Çalışma ile genel olarak sürdürülebilir kalkınma konusunda güçlü olan enstitülerin tüm alt alanlarda güçlü olamayabileceği ve genel olarak sürdürülebilir kalkınma açısından güçlü olmayan enstitülerin belirli bir alt alanda önemli bir güce sahip olabileceğini sonucuna ulaşılmıştır.

Kuldip Singh Sangwan, Mittal (2015), tarafından 113 araştırma makalesi incelenmiştir. Çalışmada, yeşil üretim ve benzer çerçevelerin kökeninin, tanımının, kapsamının, benzerlikleri ve farklılıklarının belirlenmesi amaçlanmıştır. Google akademik (Google scholer) üzerinden sürdürülebilir üretim, yeşil üretim, çevreye duyarlı üretim, çevreye karşı sorumlu imalat, çevreye zarar vermeyen imalat, temiz imalat, daha temiz üretim, kaynak ve enerji verimliliği, tedarik zinciri, kirliliğin önlenmesi ve kapalı döngü sistemine göre sürdürülebilir üretim gibi çeşitli terimler gözden geçirilerek bibliyometrik bir çalışma yapılmıştır. Sürdürülebilir üretim (sustainable production) terimi 1987 'de, 1989 'da temiz üretim (clean manufacturing), 1990'da temiz üretim (cleaner production), çevre bilincinde üretim (environmentally conscious manufacturing) ve 1991'de yeşil üretim (green management), 1993'te çevreye duyarlı üretim (environmentally responsible manufacturing), 1994'te çevreye zarar vermeyen üretim (environmentally benign manufacturing) ve 1997'de sürdürülebilir üretim (sustainable manufacturing) terimlerinin ortaya çıktığı belirlenmiştir.

Erkol Bayram, Bayram ve Karaçar (2017), sürdürülebilir turizm konusunun bibliyometrik incelemesini yapmışlardır. Sürdürülebilir turizm ile ilgili YÖK akademik veri tabanında yayınlanan 87 adet makale incelenmiş ve 40 adet makalenin çeşitli kriterlere göre bibliyometrik analizi yapılmıştır. Çalışmalar incelendiğinde; genel olarak iki yazarlı, 11-20 sayfa aralığında ve anahtar kelime sayısı dört olarak yazılmış çalışmalardan oluştuğu görülmektedir. 
Sürdürülebilir turizm alanındaki çalışmaların büyük çoğunluğunun nitel çalışmalar olduğu, nicel çalışmaların da sayısının arttırılmasının önemli olduğu sonucuna varılmıştır.

Jie Zhu, Hua (2017), yaklaşık otuz yıl önce Dünya Çevre ve Kalkınma Komisyonu (WCED) tarafından bir dizi çevresel ve sosyo-ekonomik konuya ilişkin endişeleri ele almak için entegre bir yaklaşım olarak ortaya konan sürdürülebilir kalkınma ile ilgili, 1987'den 2015'e kadar olan dönemde sürdürülebilir kalkınma araştırmalarındaki bilgi yapılarını ve gelişmeleri görsel olarak analiz etmek amacıyla, bibliyometrik bir çalışma hazırlamıştır. Alıntılanan referansları ve anahtar kelime ağlarını, kategorileri, ülkelerin dağılımını ve sürdürülebilir kalkınma araştırmalarıyla ilgili yüksek alıntıları tanımlamak ve görselleştirmek için CiteSpace programı kullanılmıştır. Analiz sonucunda; ABD ve İngiltere'nin genel olarak sürdürülebilir kalkınma ile ilgili çalışmalarda öne çıktı̆ı, Çin'in ise en yüksek yayın sayısına sahip olduğu belirlenmiştir.

Angels Niñerola, Sánchez-Rebull, Hernández-Lara (2019), tarafından sürdürülebilir turizm alanında yapılan çalışmaların bibliyometrik analizi yapılmıştır. Analizde atıf sayıları gibi çeşitli bibliyometrik göstergeler kullanılmış ve bu alandaki ana eğilimleri haritalamak amaciyla VOSviewer yazılımı kullanılmıştır. 1987-2018 döneminde Scopus'ta turizmde sürdürülebilirlik konularına ilişkin toplam 4647 makale incelenmiştir. İncelenen dergilerin, yazarların, kurumların ve anahtar kelimelerin analizi sonucunda; turizm alanındaki sürdürülebilirlik konularına ilişkin literatür önemli ölçüde artmaktadır. Sadece altı makalede 300'den fazla alıntı yapılmıştır, incelemede yer alan 614 kaynağın en önemlileri makalelerin \% 46,7'sini yayınlamış, belgeler ve alıntılar açısından $\mathrm{ABD}$ bu konuda lider ülke olarak belirlenmiştir. Anahtar kelime eğilim ağı analizine göre, sürdürülebilirlik şirketler ve turistik yerler için stratejik bir yaklaşım haline gelmektedir sonuçlarına ulaşılmıştır.

Ebru Düşmezkalender, Metin (2019), sürdürülebilirliği esas alarak; çevreye, doğaya ve kültürel kaynaklara duyarlı bir anlayışı benimseyen alternatif turizm ile ilgili makalelerin çeşitli bibliyometrik özellikler açısından incelemesini yapmıştırlar. Bu doğrultuda 2000-2018 yılları arasında Akademik (YÖK Akademik) Arama veri tabanında yayınlanan makaleler değerlendirmeye alınmıştır. Alternatif turizm anahtar kelimeleri ile tarama yapılan arama sonucunda ulaşılabilen 60 makale değerlendirilmiştir. Makaleler; araştırma türü, yayınlandığı yıl, kaynakça sayısı, yayınlandığı dergi, yazar sayısı, 
içeriği, anahtar kelime sayısı, yazarların çalıştıkları kurumlar gibi kriterler temelinde incelenmiştir. İnceleme sonucunda; alternatif turizm ile ilgili 2017 y1lında en fazla makale yayınının yapıldığı ve iki yazarlı makalelerin fazla olduğu görülmektedir. Konu ile ilgili en çok makale Atatürk Üniversitesi Sosyal Bilimler Enstitüsü Dergisi'nde yayınlanmıştır.

Mustafa Doğru, Güzeller, Çelik (2019), sürdürülebilir kalkınma ve eğitim alanı ile ilgili; 2009-2018 yılları arasında yayınlanan 7000 çalışmayı Cite Space programı kullanılarak bibliyometrik açıdan incelemişlerdir. Son 10 yıla ait eğilim ve trendler ortaya koyulmuştur. İncelenen çalışmalar Web of Science Core Collection veri tabanından "Sustainable Development" ve "Education" konu başlıklarında taranarak elde edilmiştir. Analiz sonucunda; hem yayın hem de atıf sayıları olarak alana olan ilginin 2015 yılı sonrasında çarpıcı bir şekilde arttığı, ABD'nin ülke işbirlikteliklerinde kilit rol oynadığı, en fazla atıf sayısına sahip derginin Journal of Cleaner Production olduğu belirlenmiştir.

Philip Hallinger, Chatpinyakoop (2019), sürdürülebilir kalkınma açısından yüksek öğretim ile ilgili Scopus veri tabanı üzerinden elde edilen 1459 çalışmanın bibliyometrik analizini yapmışlardır. Çalışmada, coğrafi dağılımın belirlenmesi, kilit yazarları, dergileri ve yayınları tanımlamak, elde edilen bilgi tabanının entelektüel yapısını analiz etmek ve ortaya çıkan araştırma konularını vurgulamak amaçlanlanmıştır. Betimsel analizler Scopus analitik araçları, Tableau ve MS Excel yazılım programları kullanılarak yapılmıştır. Ayrıca VOSviewer yazılımı kullanılmıştır. Çalışma Birleşmiş Milletler'in sürdürülebilir kalkınma hedeflerine ulaşmak için eğitimin küresel alanda önemli bir rol oynadığı görüşünü güçlendirmektedir.

\section{Yöntem}

Çalışmada, ekonomi alanında sürdürülebilir kalkınma konusunda yayınlanan makalelerin bibliyometrik özelliklerinin belirlenmesi amaçlanmaktadır. Web of Science (WOS) veri tabanı üzerinden konu başlı̆̆ (topic) "sustainable development" olarak arama yapılmıştır. Aynı zamanda araştırmaya konu olan makalelere ait kriterler; 2000-2019 yıllarında ekonomi alanında yayınlanmiş, İngilizce, makale türünde ve Web of Science indeks (SSCI) filtrelemesi seçilerek belirlenmiştir. 17.01.2020 tarihinde analize ait veriler için arama yapılmıştır (Webofknowledge,2020). Çalışma, yayınlanmış 2511 makaleyi kapsamakta olup, bu verilere bibliyometrik analiz uygulanmıştır. 
Bibliometrik analiz kapsamında öncelikle sürdürülebilir kalkınma alanında incelenen 2511 makalenin yıllara göre atıf sayıları ve yayınların dağılımlarına ait genel özellikler incelenmiştir. Makalelerde kullanılan anahtar kelimeler faktör analizi ile yorumlanmış, anahtar kelimelere ait trendler yıllar itibari ile incelenmiştir. Faktör analizi verilerin boyutsallığını azaltarak, verilerin daha düşük boyutlarda temsil edilmesini sağlamaktadır (Bibliometrix, 2020). Çalışmada makalelerde kullanılan anahtar kelimelerin ağırlıklı olarak birlikte kullanılıp kullanılmamasına göre birbirlerine yakınlık ve uzaklıkları faktör analizi ile kümelenerek kavramsal yapı haritası oluşturulmuştur. Sürdürülebilir kalkınma çalışmalarının kaç kaynağa atıf yaptığı ve WOS veri tabanında belirlenen çalışmalara yapılan atıf sayılarına ait dağılımları değerlendirilmiştir. Ayrıca kategorik temelde kümeleme analizleri ile yayın alanları, yazarlar, yayın kaynakları, ülkeler, enstitüler R programı ile görselleştirilerek analiz sonuçları ile birlikte ortaya konulmuştur.

\section{Analiz ve Bulgular}

Sürdürülebilir Kalkınma ile ilgili hazırlanan bibliyometrik çalışmada (Tablo 1), ekonomi alanında sürdürülebilir kalkınma "sustainable development" ile ilgili 2000-2019 yıllarına ait toplam 2511 makale Web of Science (WOS) Veri Tabanı üzerinden elde edilmiştir. 2511 makale 456 farklı dergide yayınlanmıştır. Yayın başına ortalama atıf sayısı 16,38'dir. Yazar başına düşen yayın sayısı 0,48, makale başına düşen yazar sayısı da 2,07' dir.

Tablo 1. Bulgularn Genel Özellikler

\begin{tabular}{ll}
\hline İncelenen Dönem & $2000-2019$ \\
\hline Makale & 2511 \\
\hline Dergi & 456 \\
\hline Anahtar Kelime & 2816 \\
\hline Yayın Başına Ortalama Atıf & 16,38 \\
\hline Tek Yazarlı Yayınların Sayısı & 712 \\
\hline Çok Yazarlı Yayınların Sayısı & 4475 \\
\hline Tek Yazarlı Yayın Sayısı & 805 \\
\hline Yazar Başına Düşen Yayın & 0,484 \\
\hline Makale Başına Düşen Yazar & 2,07 \\
\hline İşbirliği İndeksi & 2,62 \\
\hline
\end{tabular}


İncelenen dönem için (Şekil 1) ortalama yıllık atıf sayılarının en yüksek olduğu yıl 2000 yılıdır. 2019 yılına doğru atıf sayılarında düşüş izlenmekte olup, son yıllarda alana olan ilgi azalmaya başlamıştır yorumu yapılabilir.

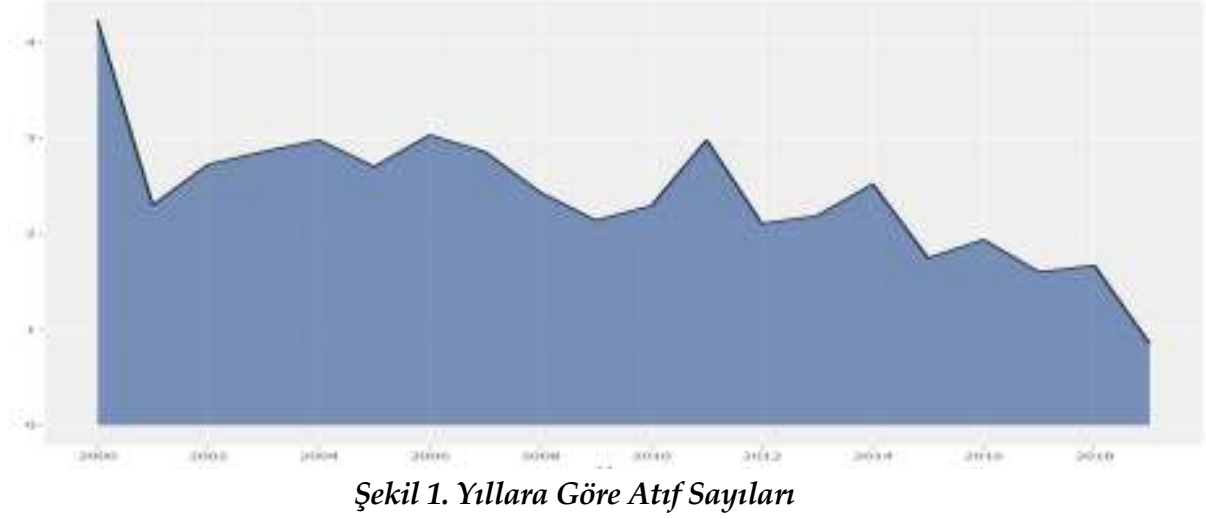

Anahtar kelimeler (keywords plus) makalelerin içeriğinde yer alan sözcükler ve sözcük gruplarına ait basliklardan ve referans kayitlarinda yer alan basliklardan toplanmis bilgileri içermektedir. Anahtar kelimeler yayınlara ait içeriklerin özetlenmesini ve daha görünür olmasını sağlamaktadır. Ayrıca yayınlanan alan ile ilgili sıkça değinilen konu ve kavramlara karşılık gelmektedir (WOS, 2020). Sürdürülebilir kalkınma alanında incelenen 2511 makalenin anahtar kelimeleri (keywords plus) göre (Şekil 2); "sürdürülebilir kalkınma (sustainable development)" en sık kullanilan kelime iken, sonrasinda sirasiyla "büyüme (growth), yönetim (management), politika (policy), etki (impact) ve tüketim (consumption)" kelimelerinin yüksek sıklıkta kullanıldığı gözlenmektedir.

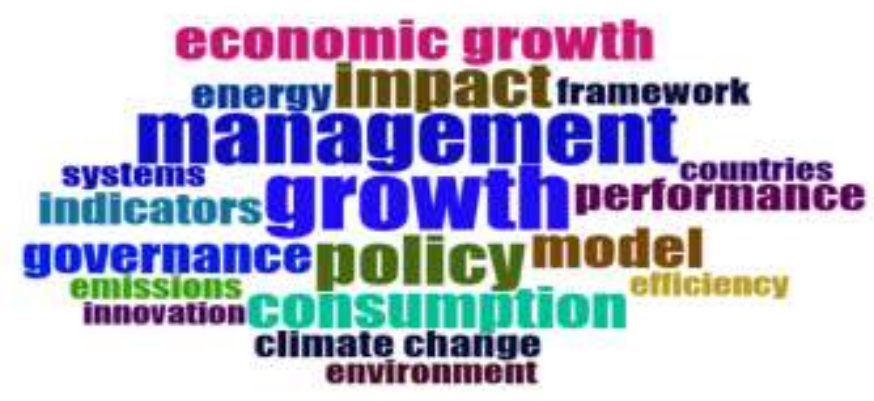

Şekil 2. Kelime Bulutu 
Şekil 3'de alana ait yapılan çalışmaların kavramsal yapılarının iki grupta kümelendiği görülmüştür. 1. Grup pazarlama, 2. Grup iktisat konularında gruplanmıştır.

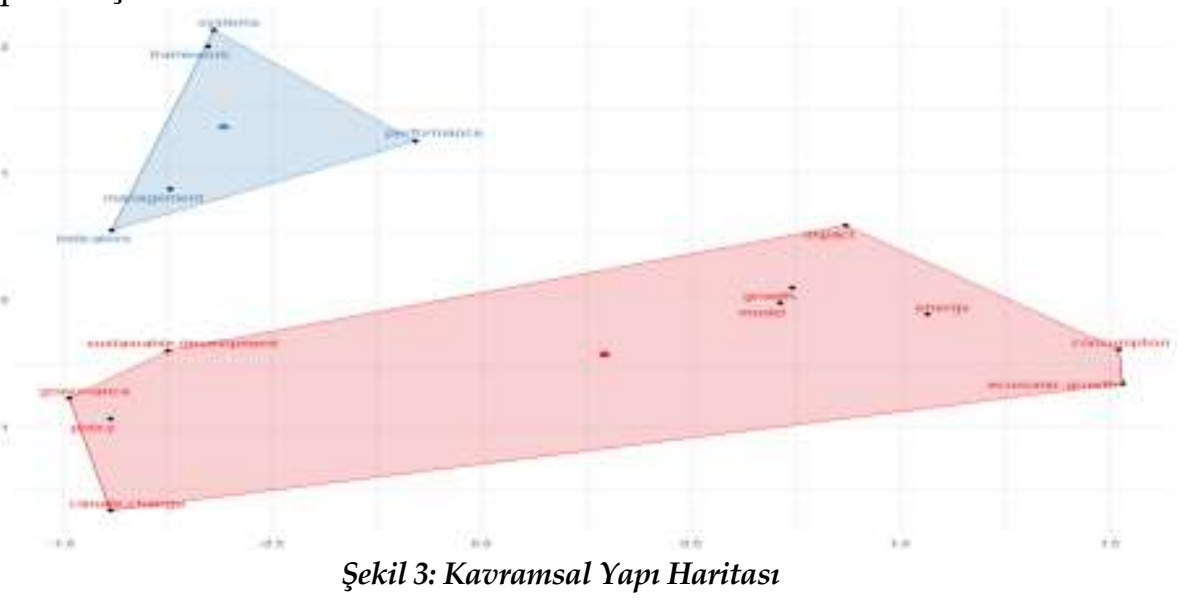

Şekil 4'de kullanılan anahtar kelimelerinin yıllar itibari ile kullanım sıklığı incelenmiş olup, "sürdürülebilir kalkınma" kelimesi alanda özellikle 2007 yıllından itibaren daha sık kullanılmaya başlanmış, 2018-2019 yıllarında ise oldukça popüler hale gelmiştir. "Etki, büyüme, politika, yönetim"

yine son yillarda alanda en fazla kullanılan kelimedir. 2018'den sonra "performans ve ekonomik büyüme" kelimelerinin kullanımında belirgin artış izlenmektedir.

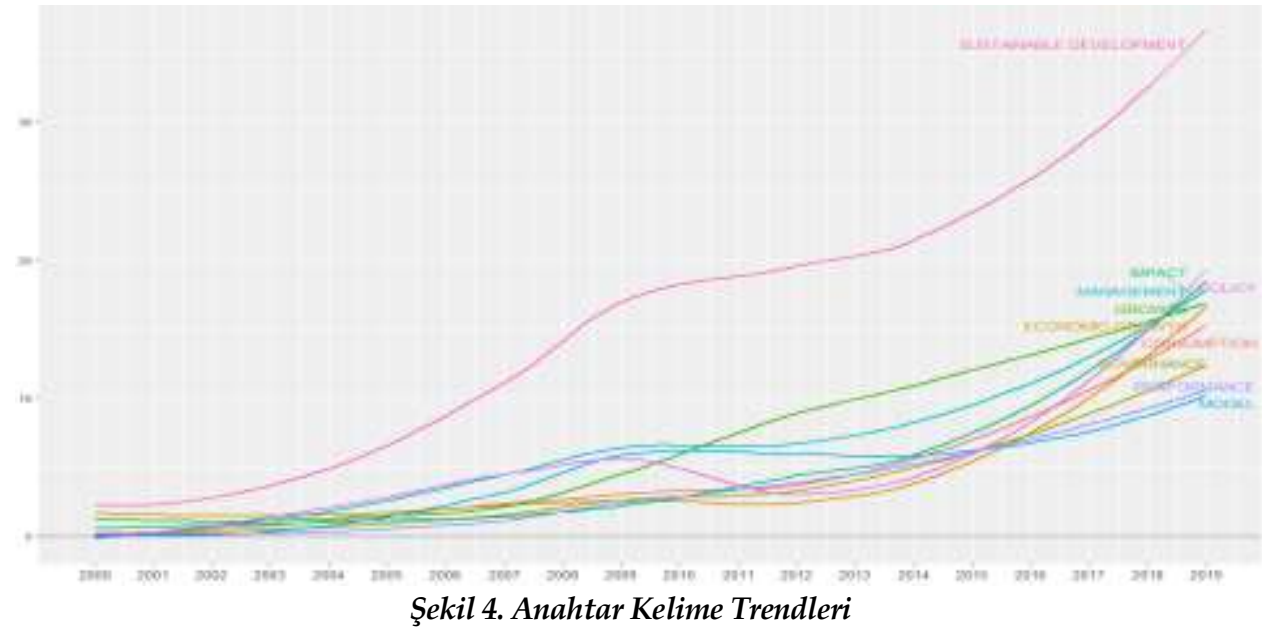


Tablo 2'de sürdürülebilir kalkınma ile ilgili 2511 makalenin yayınlandığ1 dergiler sıralanmıştır. "Energy Policy" 2000-2019 yılları arasında 343 yayın ile en fazla makale yayın yapan dergidir. "Ecological Economics" en fazla atıf alan dergidir. Ecological Economics her ne kadar yayın sayısı olarak 2. sirada yer alsada, diğer tüm değerlere bakıldığında sürdürülebilir kalkınma alanında en etkili dergidir.

Tablo 2. Kaynak Etkisi

\begin{tabular}{llllll}
\hline Kaynak & h_index & g_index & m_index & TC & NP \\
\hline Energy Polıcy & 53 & 80 & 2,52380952 & 10365 & 343 \\
\hline Ecological Economics & 56 & 99 & 2,66666667 & 11901 & 282 \\
\hline World Development & 27 & 50 & 1,28571429 & 2715 & 108 \\
\hline Amfiteatru Economic & 12 & 19 & 0,92307692 & 522 & 86 \\
\hline Futures & 22 & 41 & 1,04761905 & 1859 & 76 \\
\hline $\begin{array}{l}\text { Technological And Economic } \\
\text { Development Of Economy }\end{array}$ & 16 & 31 & 1,23076923 & 1086 & 58 \\
\hline Baltıc Journal Of Economic Studies & 2 & 3 & 0,33333333 & 19 & 55 \\
\hline Forest Polıcy And Economics & 15 & 24 & 0,75 & 709 & 51 \\
\hline Transformations In Business \& Economics & 9 & 11 & 0,5625 & 192 & 49 \\
\hline $\begin{array}{l}\text { International Environmental Agreements-Politics } \\
\text { Law And Economics }\end{array}$ & 12 & 18 & 0,92307692 & 385 & 38 \\
\hline
\end{tabular}

*TC: Toplam Atıf Sayısı, NP: Toplam Makale Sayısı

Yazar etkisinin araştırılması amacıyla h endeksi sıralamsına bakılmıştır. 2005 yılında Jorge E. Hirsch tarafından bulunan h-endeksi yayın sayısı ve yayınlara yapılan atıfları birlikte ölçen ve bilim insanlarına ait yayınları akademik yönden değerlendiren bir göstergedir. Tablo 3'de görüldüğü gibi Dalia Streimikiene en fazla makale yayını (14) yapan ve h endeksi sıralamasında önde gelen yazardır. İbrahim Dinçer ise; yayın sayısı (3) değerlendirmesine göre diğer bazı yazarların gerisinde olmasına ragmen, alan ile ilgili en çok atıf alan (757) yazardır.

Tablo 3. Yazar Etkisi

\begin{tabular}{llllll}
\hline Yazar & h_index & g_index & m_index & TC & NP \\
\hline Streımıkıene Dalıa & 7 & 13 & 0,5 & 175 & 14 \\
\hline Zavadskas Ek & 7 & 8 & 0,63636364 & 481 & 8 \\
\hline Ciegıs R & 6 & 9 & 0,46153846 & 203 & 9 \\
\hline Hamilton K & 5 & 6 & 0,33333333 & 85 & 6 \\
\hline Balezentıs A & 5 & 5 & 0,45454546 & 156 & 5 \\
\hline Balezentis T & 5 & 5 & 0,45454546 & 156 & 5 \\
\hline Maler Kg & 5 & 5 & 0,277777778 & 295 & 5 \\
\hline Onishı A & 5 & 5 & 0,25 & 47 & 5 \\
\hline
\end{tabular}




\begin{tabular}{|c|c|c|c|c|c|}
\hline Tvaronaviciene $\mathrm{M}$ & 5 & 5 & 0,38461539 & 164 & 5 \\
\hline Wang C & 5 & 5 & 0,35714286 & 357 & 5 \\
\hline Yazar & $h \_$index & g_index & m_index & TC & NP \\
\hline Dincer I & 3 & 3 & 0,15789474 & 757 & 3 \\
\hline Rennıngs K & 2 & 2 & 0,0952381 & 733 & 2 \\
\hline Robınson J & 3 & 3 & 0,16666667 & 708 & 3 \\
\hline Zavadskas Ek & 7 & 8 & 0,63636364 & 481 & 8 \\
\hline Bohrınger $\mathrm{C}$ & 2 & 2 & 0,13333333 & 449 & 2 \\
\hline Rotmans J & 3 & 3 & 0,14285714 & 442 & 3 \\
\hline Jochem Pep & 1 & 1 & 0,07142857 & 371 & 1 \\
\hline Turskıs Z & 2 & 2 & 0,18181818 & 368 & 2 \\
\hline Wang C & 5 & 5 & 0,35714286 & 357 & 5 \\
\hline Chen Wy & 3 & 3 & 0,16666667 & 338 & 3 \\
\hline
\end{tabular}

Şekil 5'te yer alan üç alan grafiği bize Streimikiene'nin alan ile ilgili çalışmalarında en fazla sürdürülebilir kalkınma (sustainable development), ekonomik büyüme (economic growth) ve yoksulluk (poverty) anahtar kelimelerini kullandığını ve Ecological Econ, Energy Policy, Energy Economics gibi önde gelen dergilerde yayınlarının olduğunu göstermektedir.

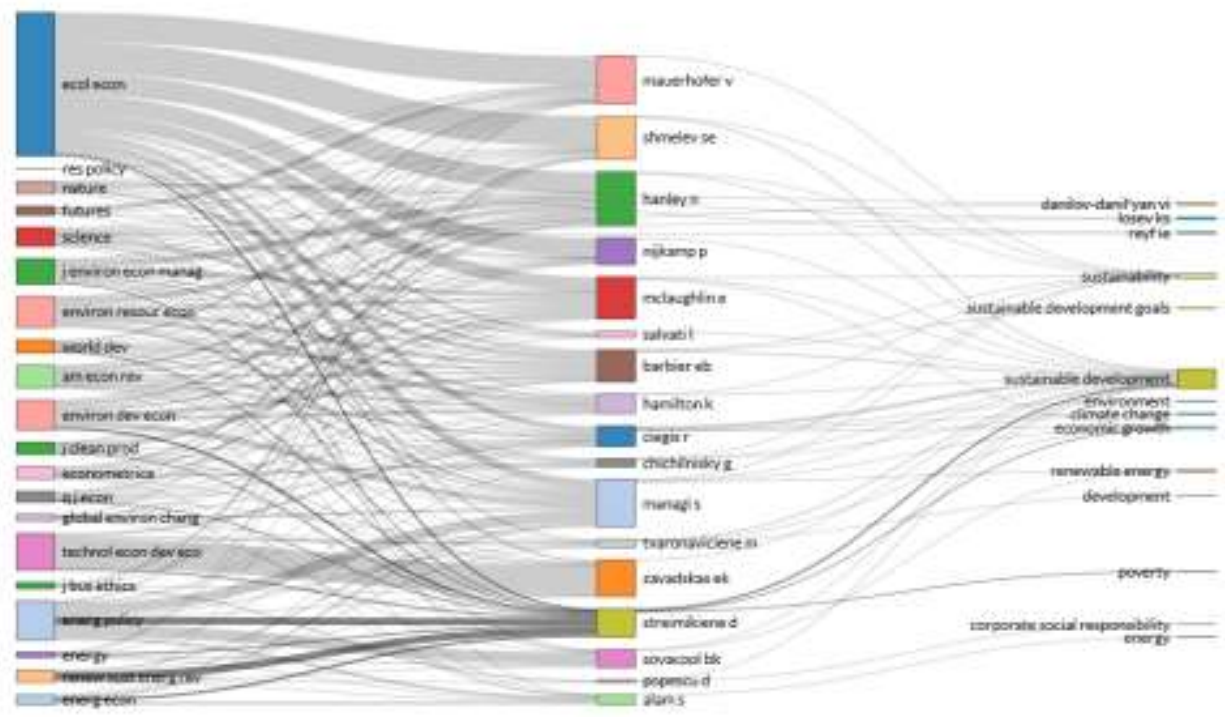

Şekil 5: Yazar, Referans ve Anahtar Kelimelere Ait Üç Alan Grafiği 
Sürdürülebilir kalkınma ile ilgili en fazla atıf alan çalışmanın yapıldığı ülkeler Tablo 4'te sıralanmıştır. İngiltere, Amerika (ABD), Çin, Almanya, Hollanda ilk 5 ülke olup, Türkiye alanla ilgili toplam atıf saysında 13. sırada yer almaktadır.

Tablo 4: En Fazla Atıfta Bulunan Ülkeler

\begin{tabular}{lll}
\hline Ülke & Toplam Atıf Sayısı & Ortalama Makale Alıntıları \\
\hline İngiltere & 4601 & 23,237 \\
\hline ABD & 3987 & 15,948 \\
\hline Çin & 3696 & 20,087 \\
\hline Almanya & 2824 & 34,864 \\
\hline Hollanda & 2796 & 31,067 \\
\hline İsviçre & 1784 & 42,476 \\
\hline Litvanya & 1692 & 18,391 \\
\hline Kanada & 1652 & 29,5 \\
\hline Fransa & 1507 & 18,157 \\
\hline İsveç & 1212 & 24,24 \\
\hline İtalya & 1069 & 14,446 \\
\hline İspanya & 954 & 21,2 \\
\hline Türkiye & 878 & 26,606 \\
\hline Avustralya & 870 & 10 \\
\hline Yunanistan & 870 & 45,789 \\
\hline
\end{tabular}

Sürdürülebilir kalkınma alanına ait ortak yazarlık yapan ülkelerin yoğunlukları Şekil 6'da gösterilmiştir. Alan ile ilgili en fazla birlikte çalışma yapan ülkeler; Çin ve ABD (f: 29)'dır. ABD ve İngiltere (f: 22), ABD ve Hollanda (f: $14), A B D$ ve Almanya (f: 13$)$, Çin ve İngiltere (f: 12$)$ ve $A B D$ ve İsviçre (f: 12)' dir. Sonuç olarak ABD, İngiltere, Çin, Almanya, Hollanda ve İsviçre alana en fazla katkı yapan ülkelerdir.

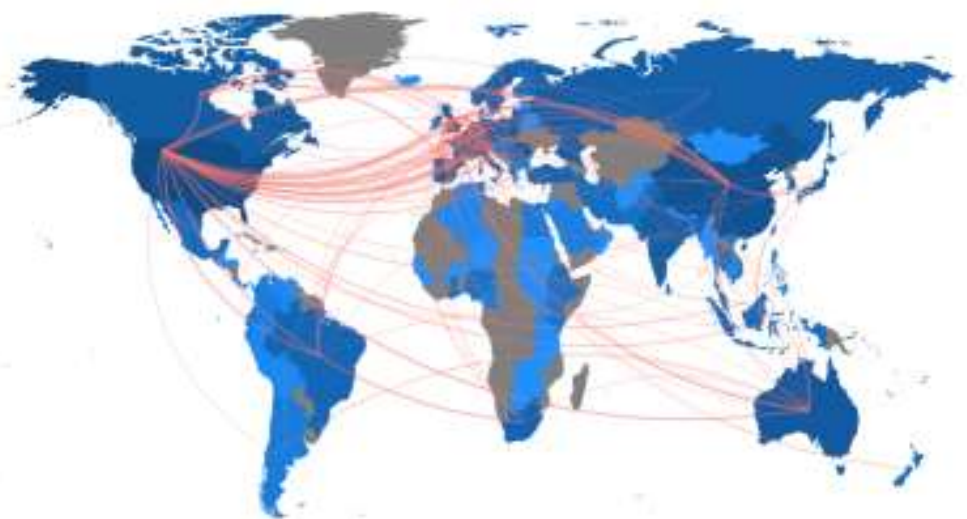

Şekil 6. Ülkeler İşbirliği Haritası 
2000-2019 yılları arasında sürdürülebilir kalkınma alanında yayın yapan üniversite sıralamasına bakıldığında (Tablo 5); en fazla yayın yapan üniversite Romanya'da bulunan Bucharest Üniversitesidir. Yayın sayılarına göre s1ralamada ilk 5 üniversitenin 2'si Litvanya' da bulunan üniversitelerdir.

Tablo 5. Yayın Sayılarına Göre Üniversiteler

\begin{tabular}{lll}
\hline Üniversiteler/Kurumlar & Ülkeler & Makale Sayılari \\
\hline The Bucharest University of Economic Studies & Romanya & 58 \\
\hline Vilnius Gediminas Technical University & Litvanya & 49 \\
\hline Amsterdam Vrije Üniversitesi & Hollanda & 35 \\
\hline University of Oxford & İngiltere & 28 \\
\hline Vilnius University & Litvanya & 28 \\
\hline University of Cambridge & İngiltere & 24 \\
\hline World Bank & ABD & 23 \\
\hline Tsinghua University & Çin & 22 \\
\hline Autonomous University of Barcelona & İspanya & 20 \\
\hline Kyushu University & Japonya & 18 \\
\hline
\end{tabular}

\section{Sonuç}

Web of Science (WOS) veri tabanı üzerinden 2000-2019 yıllarına ait ekonomi alanında İngilizce makale türünde "sürdürülebilir kalkınma (sustainable development)" başlı̆g ile taranarak bulunan 2511 makalenin R programı kullanılarak bibliyometrik analizi yapılmış, son 20 yıllık dönemde ilgili alandaki gelişmeler, trendler, önde gelen dergi, enstitü ve ülkelere ait analiz sonuçları görselleştirilerek ortaya konulmuştur. İncelenen 2511 makale 456 farklı dergide yayınlanmıştır. Yayın başına ortalama atıf sayısı 16,38'dür. Makale başına düşen yazar sayısı da 2,07'dir. Son 20 yılda alana ait ilginin en yüksek olduğu yıl 2000 yılı olup, son yıllarda atıf sayılarında düşüş yaşanmıştır. Makalelerde "sürdürülebilir kalkınma (sustainable development)" en sık kullanılan kelime iken, sonrasında sırasıyla "büyüme (growth), yönetim (management), politika (policy), etki (impact) ve tüketim (consumption)" kelimelerinin yüksek sıklıkta kullanıldığı gözlenmektedir. Son yıllarda yapılan çalışmalarda ağırlıklı kullanılan kelimeler incelendiğinde de; 2007 yılından itibaren "sürdürülebilir kalkınma" kelimesi alanda daha sık kullanılmaya başlanmış, 2018-2019 yıllarında ise oldukça popüler hale gelmiştir. "Etki, büyüme, politika, yönetim" yine son yıllarda alanda en sik kullanılan kelimelerdir. "Performans ve ekonomik büyüme" ise; 2018' den sonra daha sik kullanılan kelimelerdir. Alan ile ilgili yapılan çalışmaların kavramsal yapılarının iki grupta kümelendiği görülmüştür. 1. Grup pazarlama, 2. Grup iktisat konularında gruplanmıştır. 
Dalia Streimikiene en fazla makale yayını yapan ve h endeksi sıralamasında önde gelen yazardır. İbrahim Dinçer ise; yayın sayısı değerlendirmesine göre diğer bazı yazarların gerisinde olmasına rağmen alan ile ilgili en çok atıf alan yazardır. Dalia Streimikiene'nin alan ile ilgili çalışmalarında en fazla sürdürülebilir kalkınma (sustainable development), ekonomik büyüme (economic growth) ve yoksulluk (poverty) anahtar kelimelerini kullandığını ve Ecological Econ, Energy Policy, Energy Economics gibi önde gelen dergilerde yayınlarının olduğu görülmektedir. "sürdürülebilir kalkınma" ile ilgili en fazla çalışmanın yapıldığı ülkeler; İngiltere, ABD, Çin, Almanya, Hollanda olup, Türkiye alanla ilgili toplam atıf sayısında 13. sırada yer almaktadır. Alan ile ilgili en fazla ortak yazarlık yapan ülkeler incelendiğinde; ABD, İngiltere, Çin, Almanya, Hollanda ve İsviçre alana en fazla katkı yapan ülkelerdir. En fazla yayın yapan üniversite; Romanya' da bulunan Bucharest Üniversitesidir. Yayın sayılarına göre sıralamada ilk 5 üniversitenin 2'si Litvanya'da bulunan üniversitelerdir. 2511 makalenin yayınlandığı dergiler arasında "Energy Policy" en fazla makale yayını yapan dergidir. "Ecological Economics" en fazla atıf alan dergidir. Ecological Economics her ne kadar yayın sayısı olarak 2. s1rada yer alsada, diğer tüm değerlere bakıldığında sürdürülebilir kalkınma alanında en etkili dergidir.

Çalışmaya ait bazı sınırlılıklar bulunmaktadır. Analiz sonuçlarının elde edildiği 2511 makaleye 17.01.2020 tarihinde ulaşılmış olup, bu tarihten sonra veritabanına eklenen yeni makaleler ile yayınların dağılımı, atıf sayıları, yazar, ülke sayıları, anahtar kelimeler ve bu kelimelerin sayısı farklılık gösterebilecektir. Dolayısıyla farklı bulguların elde edilmesi mümkün olabilecektir. Çalışmada seçilen makaleler; ekonomi alanında, ingilizce, makale türünde ve Web of Science indeksi (SSCI) olarak filtrelenerek analiz edilmiş olup, gelecekte yapılacak çalışmalarda araştırmacılar sürdürülebilir kalkınma alanına ait; yayın türü, dil ve Web of Science indekslerini (SSCI, A\&HCI, SCI-Expanded, CPCI-S, CPCI-SSH, ESCI) daha kapsamlı olarak seçerek kapsamı daha geniş bir çalışma hazırlayabilirler. 


\title{
EXTENDED ABSTRACT
}

\section{Bibliometric Analysis of Publications in Sustainable Development with R Program}

\author{
Ceren Kocabaş - Gamze Alkan \\ Akdeniz University
}

As from 20th century, the countries has started to develop in economic and social aspects while the world population has been increasing. However because the wants are limitless and the resouces are scarce, and the world population grows faster, this causes the decrease in natural resources and the changes in climate. Faster growing of industrialization and urbanization, the development of the economies of the countries and the modernization in agriculture shaked the resource-want balance. The effort of gaining social welfare took the future of humanbeings under hypothec. This revealed the notion of sustainable development. This notion in fact was declared firstly in 1987 during The World Environment and Development Commission, and since then became the most acceptable and the most used notion. The targets of the sustainable development in the report of The World Environment and Development Commission in 1987 were lined up as follows: Reviving growth, changing the quality of growth, finding jobs, food, energy, satifying the basic needs in the water and health issues, protecting the resouce basis and enrichment, directing the technology again and managing the risks, combining the environment and economy in the process of making decision. The sustainable development the recognition of which increased especially at the end of 20th century became such a global application plan by signing the international agreements in the years of 1990s.

In this study, the bibliometric analysis of 2511 articles, which were gained by scanning the title of "sustainable development" in the type of English articles in the field of economics between the years of 2000-2019 within the data base of Web Of Science (WOS) were analyzed by using $\mathrm{R}$ programme. The term of bibliometric was first declared by Alan Pritchard in 1969. The first bibliometric study was done by Cole and Eales in 1917. They made a statistical analysis of the researches published in the field of comparative anatomy 
between the years of 1550-1860. The basic aim of the bibliometry is analyzing with the numeric methods for the purpose of enchancing the findings of the scientific communication and enchancing the scientific documentation, base on the specific criterions of the publications and documents such as the journals and books which were published in different times.

In the bibliometric analysis of this study, the developments in the related fields during 20 years period, trends, the leading journals, the analysis results belonging to the institutions and countries were presented by visualizing. The 2511 articles analyzed were published in 456 different journals. The average number of citations for each publication was 16,38 . The number of writers for each article was 2,07. The notion of "sustainable development" was the most used word in the articles, following the words of "growth", "management", "policy", "impact" and "consumption", which were observed that they were used in high frequency. When analyzing the predominantly most used words in the recent studies in the last years, it was observed that the notion of "sustainable development" was started to be used frequently as from 2007, and became quite popular in the years of 2018-2019. "The impact, growth, policy, management" were the words which were used most frequently in recent years. On the other hand, "performance and economic growth" were the words which were used most frequently after 2018. It was seen that the conceptional structure of the studies done concerning the field clustered in two groups. The first group was aggregated in the issue of marketing, second group was aggregated in the issue of economics. Dalia Streimikiene was the writer who made the most of the publications and was the leading writer in the sorting of $h$ index. Although Ibrahim Dinçer was at the behind of other writers in the evaluation of the number of the publications, he was the writer who took most of the citations. The countries about which the most of the studies were done were England, USA, China, Germany and Holland, where Turkey was at 13. place in the number of total citations about the field. When analyzing the countries which had most of the joint authors concerning the field, USA, England, China, Germany, Holland and Switzerland were the countries who contributed most to the field. The university which made most of the publications was The University of Bucharest. The "Energy Policy" was the journal which made most of the publications among the journals which includes 2511 articles. The "Ecological Economics" was the journal which took most of the citations. Although Ecological Economics 
was at second place for the criterion of the number of publication, it was the most influential journal in the field of sustainable development when looking at all other values.

\section{Kaynakça / References}

Aksu, C., (2011). Sürdürülebilir kalkınma ve çevre. Güney Ege Kalkınma Ajansı, ss:33

Bahçeci, H.I, Görmez, K., (2019). Sürdürülebilir kalkınma vs ekolojik düşünce. Uluslararası Toplum Araştırmaları Dergisi, 10(17), 2301-2323

Baykal, H., Baykal, T., (2008). Küreselleşen Dünya'da çevre sorunları. Mustafa Kemal Üniversitesi Sosyal Bilimler Enstitüsü Dergisi, 5(9), 1-17

Düşmezkalender, E., Metin, M. (2019). Alternatif turizme yönelik bibliyometrik bir araştırma. Selçuk Üniversitesi Sosyal Bilimler Meslek Yüksekokulu Dergisi, 22(2), 813-824. https://doi.org/10.29249/selcuksbmyd.546044.

Doğru, M., Güzeller, C. O., Çelik, M. (2019). Geçmişten günümüze sürdürülebilir kalkınma ve eğitim alanında: Bibliyometrik bir analiz. Adryaman Üniversitesi Eğitim Bilimleri Dergisi, 9(1), 42-68. doi: https://doi.org/10.17984/adyuebd.515009.

Erkol Bayram, G., Bayram, A. T., Karaçar, E. (2017). Sürdürülebilir turizm: Bibliyometrik analiz. 1. Uluslararası Sürdürülebilir Turizm Kongresi, 23-25 Kasım 2017, Kastamonu, 179-186

Hallinger, P., Chatpinyakoop, C. A. (2019). Bibliometric review of research on higher education for sustainable development, 1998-2018. Sustainability, 11(2401). doi:10.3390/su11082401.

Hassan, S.U., Haddawy, P., Zhu, J. (2014). A bibliometric study of the World's research activity in sustainable development and its sub-areas using scientific literature. Scientometrics, 99(2), 549-79

Niñerola, A., Sánchez Rebull, M.V., Hernández-Lara, A.B. (2019). tourism research on sustainability: A bibliometric analysis. Sustainability, 11(1377). doi:10.3390/su11051377.

Osareh, F. (1996). Bibliometrics, citation analysis and co-citation analysis: A review of literature I. Libri, 46(3), 149-158. doi: 10.1515/libr.1996.46.3.149

T.C Strateji ve Bütçe Başkanlığı. (t.y). Sürdürülebilir kalknma hakkında temel bilgiler, 15.02.2020 tarihinde http://www.surdurulebilirkalkinma.gov.tr/temel-tanimlar/ adresinden alındı. 
Hassan, S.U., Haddawy P., Kuinkel P., Sedhai S. (2011). A bibliometric study of research activity in sustainable development. in Proceedings of 13th Conference of the International Society for Scientometrics and Informetrics (ISSI2011), 2, 996998

Sangwan, K.S., ve Mittal, V.K. (2015). A bibliometric analysis of green manufacturing and similar frameworks. Manag. Environ. Qual., 26(4), 566-587. doi 10.1108/MEQ-02-2014-0020.

Zhu, J., Hua, W. (2017). Visualizing the knowledge domain of sustainable development research between 1987 and 2015: A bibliometric analysis. Scientometrics 10, 893-914. doi: http://dx.doi.org/10.1007/s11192-016-2187-8

\section{Kaynakça Bilgisi / Citation Information}

Kocabaş, C. ve Alkan, G. (2020). Sürdürülebilir kalkınma alanındaki yayınların r programı ile bibliyometrik analizi. OPUS-Uluslararası Toplum Araştırmaları Dergisi, 16(Özel Say1), 3714-3732. DOI: 10.26466/opus.707518 